\title{
Safe Haven Configurations for Deep Space Transit Habitats
}

\author{
David Smitherman ${ }^{*}$ Tara Polsgrove ${ }^{\dagger}$, and Justin Rowe ${ }^{*}$ \\ NASA Marshall Space Flight Center, Huntsville, AL, 35812 \\ and \\ Matthew Simon, $\mathrm{PhD}^{\S}$ \\ NASA Langley Research Center, Hampton, VA, 23681
}

\begin{abstract}
Throughout the human space flight program there have been instances where systems failures resulting in smoke, fire, and pressure loss have occurred onboard space vehicles, putting crews at risk for loss of mission and loss of life. In most instances the missions have been in Low-Earth-Orbit (LEO) or Earth-Moon vicinity, with access to multiple volumes that could be used to quickly seal off the damaged module or access escape vehicles for return to Earth. For long duration missions beyond LEO, including Mars transit missions of about 1100 days, the mass penalty for multiple volumes and operating in an environment where a quick return will not be possible have been concerns. In 2016, a study was done to investigate a variety of dual pressure vessel configurations for habitats that could protect the crew from these hazards. It was found that with a modest increase in total mass it should be possible to provide significant protection for the crew. Several configurations were considered that either had a small safe haven to provide 30-days to recover, or a full duration safe haven using two equal size pressure vessel volumes. The 30-day safe haven was found to be the simplest, yielding the least total mass impact but still with some risk if recovery is not possible during that timeframe. The full duration safe haven was the most massive option but provided the most robust solution. This paper provides information on the various layouts developed during the study and provides a discussion of the findings for implementing a safe haven in future habitat designs.
\end{abstract}

$\begin{array}{ll}\text { EMC } & \text { Evolvable Mars Campaign } \\ \text { EUS } & \text { Exploration Upper Stage } \\ \text { EVA } & \text { Extra-Vehicular Activity } \\ \text { ISS } & \text { International Space Station } \\ \text { IVA } & \text { Intra-Vehicular Activity } \\ \text { kg } & \text { kilograms } \\ \text { LEO } & \text { Low-Earth-Orbit } \\ \mathrm{m} & \text { meter }\end{array}$

Nomenclature

Mgt. Management

MOI Mars Orbital Insertion

SEP Solar Electric Propulsion

SLS Space Launch System

TEI Trans-Earth Injection

TLI Trans-Lunar Injection

TMI Trans-Mars Injection

\section{Introduction}

$\mathrm{F}$ UTURE Mars missions will require a transit habitat that can support a crew of 4 for about 1100 days without major mishaps or failures. Smoke and fire on board are a concern, but the Space Station experience has provided great insight into designs and technologies that mitigate that risk. Another concern for Mars missions is pressure loss due to a small asteroid strike or a collision with another spacecraft during docking or undocking operations. Collision concerns at the International Space Station are somewhat mitigated by the extensive procedures and experience of ground operations and astronaut crews, and the availability of multiple modules and multiple return vehicles. For Mars

\footnotetext{
* Technical Management, Advanced Concepts Office, ED04, AIAA Senior Member.

${ }^{\dagger}$ Aerospace Engineer, Science \& Technology Office, ST24, AIAA Member.

* Mechanical Engineer, ESSSA Contract, Advanced Concepts Office, ED04, AIAA Member.

$\S$ Aerospace Engineer, Space Mission Analysis Branch, MS:462, AIAA Member.
} 
missions, ground operations will be limited, quick return will not be possible, and the need for multiple volumes have yet to be determined. So, the risk of a collision during these deep space missions could yield disastrous results. Table 1 depicts one of several possible Mars mission scenarios with crew docking operations in Earth and Mars orbits. These operations yield up to 14 possible docking and undocking events in a single mission where a collision at any step along the way could yield both loss of mission and loss of crew for transit habitat designs without safe haven capabilities.

Table 1. Potential Mars Mission Docking and Undocking Operations.

\begin{tabular}{|c|c|l|}
\hline Event No. & Location & Crew / Vehicle Operations \\
\hline 1 & High Earth Orbit & Crew docks Orion to Transit Habitat and boards \\
\hline 2 & High Earth Orbit & Orion undocks and Transit Habitat initiates TMI burn \\
\hline 3 & Mars Orbit & Transit Habitat rendezvous and docks with return propulsion stage \\
\hline 4 & Mars Orbit & Mars Orbital Insertion (MOI) stage undocks with Transit Habitat \\
\hline 5 & Mars Orbit & Crew docks Transit Habitat with Phobos Taxi and boards for Phobos mission \\
\hline 6 & Mars Orbit & Taxi undocks from Transit Habitat and transfers to Phobos \\
\hline 7 & Mars Orbit & Crew docks Taxi to Transit Habitat and boards \\
\hline 8 & Mars Orbit & Taxi undocks from Transit Habitat \\
\hline 9 & Mars Orbit & Crew docks Transit Habitat with Mars Lander \\
\hline 10 & Mars Orbit & Lander undocks from Transit Habitat and descends to Mars surface \\
\hline 11 & Mars Orbit & Crew docks Mars Ascent Vehicle (MAV) with Transit Habitat and boards \\
\hline 12 & Mars Orbit & MAV undocks and Transit Habitat initiates Trans-Earth Injection \\
\hline 13 & High Earth Orbit & Crew docks Transit Habitat with Orion \\
\hline 14 & High Earth Orbit & Orion undocks from Transit Habitat and returns crew to Earth \\
\hline
\end{tabular}

The safe haven concept was inspired to help resolve these issues by determining the mass impact for providing a second pressure vessel that the crew could move into to give them time to recover from a mishap, and designed in a configuration that could be launched efficiently on the Space Launch Systems (SLS). Multiple approaches were explored to provide a variety of configurations for the safe haven concept. Configurations considered included a single pressure vessel with an internal bulkhead, dual pressure vessels of the same size, and a primary pressure vessel with a second smaller unit for the safe haven. Life support options included duplicate closed loop life support systems for full duration in either volume, and a single closed loop life support system in the primary volume with an open loop life support for 30-day duration in a smaller secondary volume.

\section{Save Haven Configurations}

The starting point for the safe haven concepts developed in this study came from the Mars Transit Habitat baselined in the Advanced Exploration Systems, Evolvable Mars Campaign (EMC) as shown in Fig. 1, configuration 1a. ${ }^{1,2}$ Internal layouts and manufacturing considerations were then developed further as part of configuration $1 \mathrm{~b}$ along with subsystems sizing and mass estimates that could then be compared to a variety of alternative layouts for the safe haven designs.

Configurations 1a represents the standard single volume monolithic habitat planned for Mars missions in the 2030s, which includes an advanced closed loop life support system designed to support 4 crew for 1100 days. $^{3}$ Configuration $1 \mathrm{~b}$ is a revision of that same concept using current technologies, which required a little more volume for stowage, uses structures and end domes based on current SLS manufacturing standards, and uses current life support systems from the International Space Station. These differences increased the mass and volume slightly, but the updated design established a baseline that could then be more easily compared to additional configurations with integrated safe havens to determine the real mass implications for a safe haven design.

The interior layout for the monolithic design is arranged in a vertical orientation on two deck levels. The lower deck includes all of the crew systems for research, vehicle controls, galley, exercise, and waste management. The life support systems are located below the floor in the lower end dome. Translation from the lower deck to the upper deck is through a large opening in the center of the module providing a more open layout approach. The upper deck includes the four crew quarters with stowage packed in between and around the quarters to further enhance radiation protection for the crew. ${ }^{4}$ 


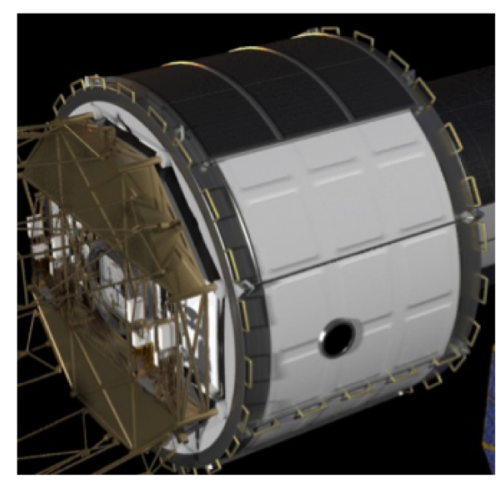

Exterior View of Configuration 1a

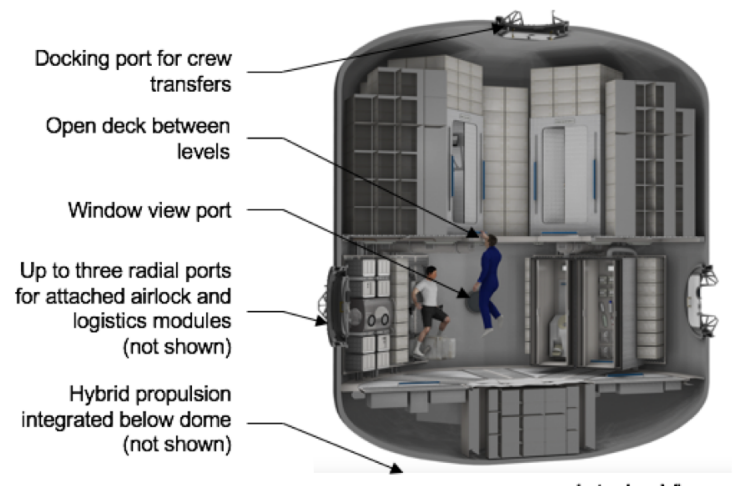

Interior Views of Configuration 1
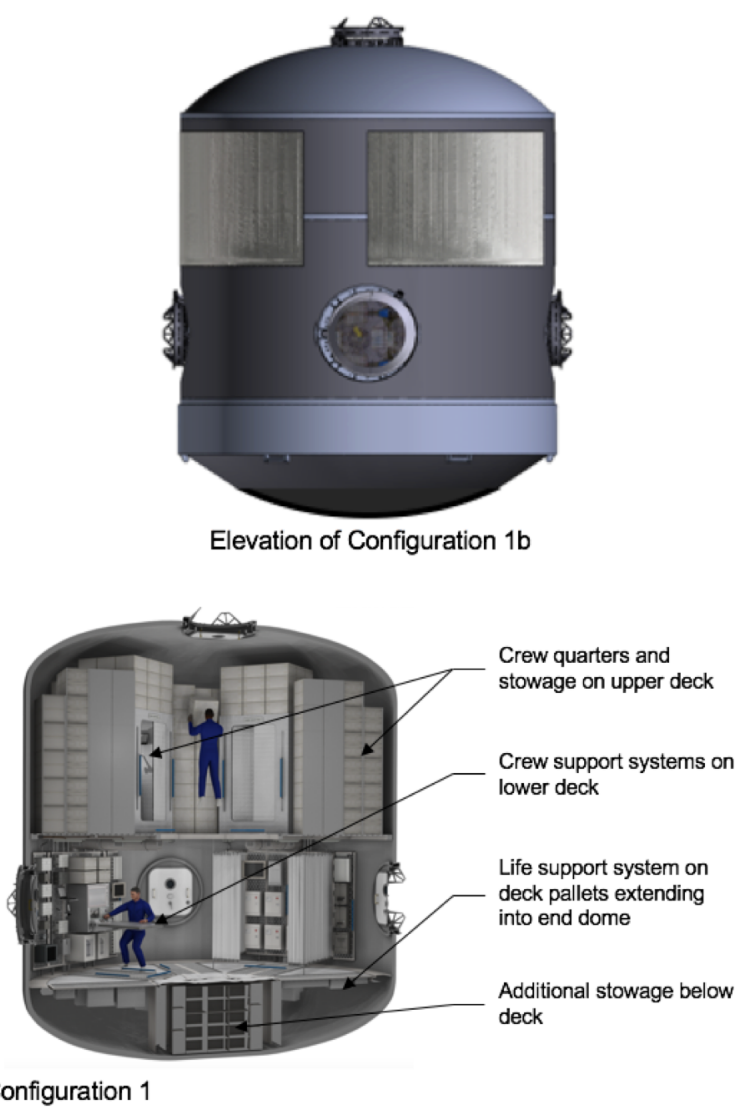

Figure 1. EMC Mars Transit Habitat. The advanced habitat in configuration la designed with technology assumptions for the 2030s was revised to current standards in configuration $1 \mathrm{~b}$ to help establish a baseline for safe haven mass calculations in a variety of possible layouts illustrated in configurations 2 through 5.

Configuration 2, shown in Fig. 2, has the same exterior appearance as configuration $1 \mathrm{~b}$ but creates a safe haven by installation of an internal bulkhead between the upper and lower decks with an intra-vehicular activity (IVA) airlock, and a duplicate closed loop life support system that provides for full duration capability in either volume. The crew systems are split between the two deck levels to minimize loss if evacuation from one side is required. Each level includes two crew quarters and about half the stowage, a split in the crew systems functions, and a complete life support systems packaged in the decks over the dome and bulkhead for each level.

In the event of pressure loss in one side, duplicate life support and avionics are provided on each side to sustain life for the full duration and provide communications and vehicle control systems on each side. In concept, the IVA airlock provides passage through the bulkhead for transfer of stowage and equipment needed for the duration of the flight. Conveniences like research equipment, hygiene, and exercise, might be lost or downgraded in one side or the other, but with access to the unpressurized volume it is believed that operational workarounds can be found to resolve life sustaining issues.

Internal and external repairs might be possible so the habitat is designed for both internal and external access to the pressure vessel walls. The interior uses a modular pallet system that can tilt up from the floors above the domes and away from the walls. An external inflatable airlock is also available at one of the radial hatches (not shown), to provide EVA crew access to the entire pressure shell for repair operations.

When configurations $1 \mathrm{~b}$ and 2 are compared the basic increase in mass for a full duration safe haven can be found. It came to $5,969 \mathrm{~kg}$, which included $1700 \mathrm{~kg}$ for the additional structure required for the internal bulkhead and airlock, $742 \mathrm{~kg}$ for the duplicate avionics required for each volume, and 3,527 kg for the duplicate life support system. So, for around $6,000 \mathrm{~kg}$ it seems reasonable to assume that a full duration safe haven can be provided in most Mars transit habitat designs that will protect the crew from smoke, fire, and pressure loss for the duration of their mission. The 
advanced life support system planned for the 2030s included in the EMCs Configuration 1a is about $1000 \mathrm{~kg}$ lower in mass, which would bring the total impact of the safe haven mass down to only $5,000 \mathrm{~kg}$.

These estimates do not include duplicate food stowage systems. It is assumed that the crew will be able to pass through the internal airlock to collect the supplies they need. Which, also assumes that the stowed provisions are not permanently damaged by exposure to smoke, fire, or vacuum. These operational details and concerns are part of the recommendations for further analysis of safe haven concepts.

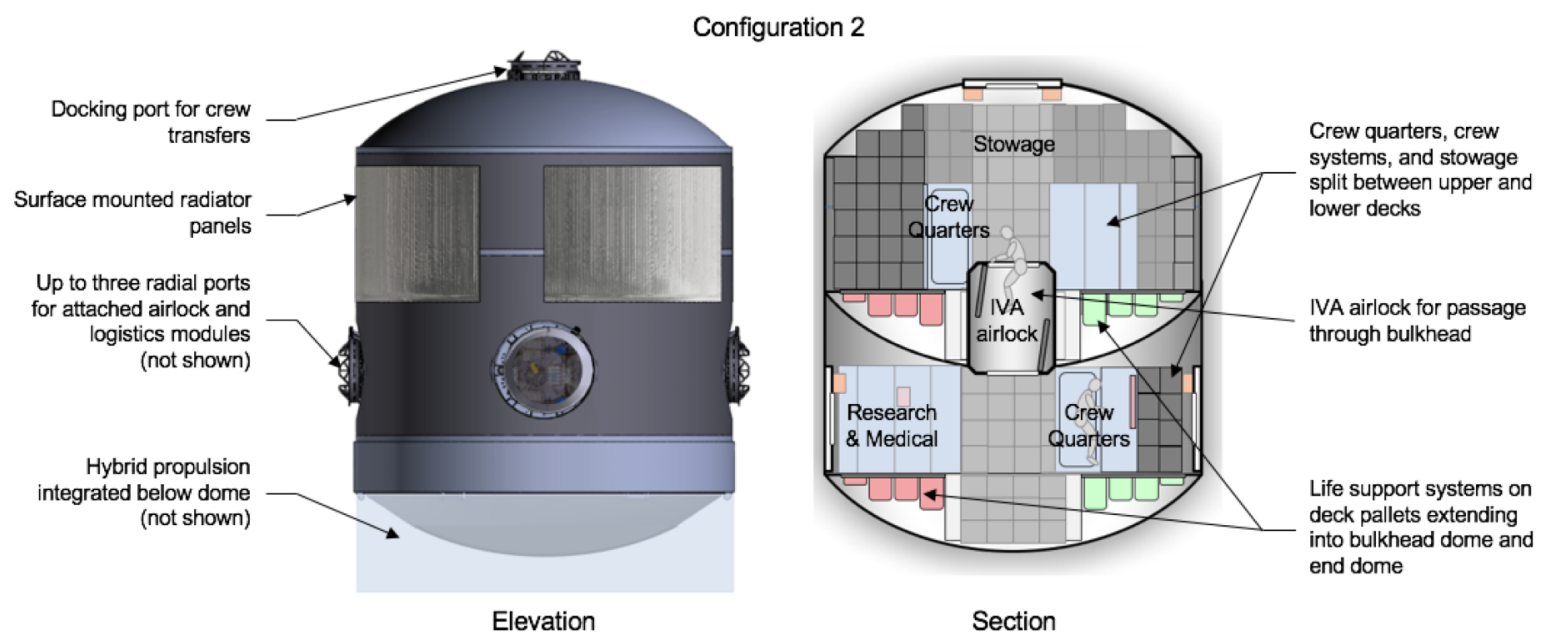

Figure 2. Common Bulkhead Habitat. Configuration 2 added an internal bulkhead and airlock between the upper and lower decks with duplicate life support systems to provide full duration capability in either volume.

Configuration 3 shown in Fig. 3 is the same as configuration 2, but uses two pressure vessels of equal volume. When configuration 3 is compared to configuration 2 it was found to be about $300 \mathrm{~kg}$ more massive, all attributable to the additional structures mass. This comparison indicates that manufacturing simplifications for configuration 3 may be worth further investigation for the dual pressure vessel option.

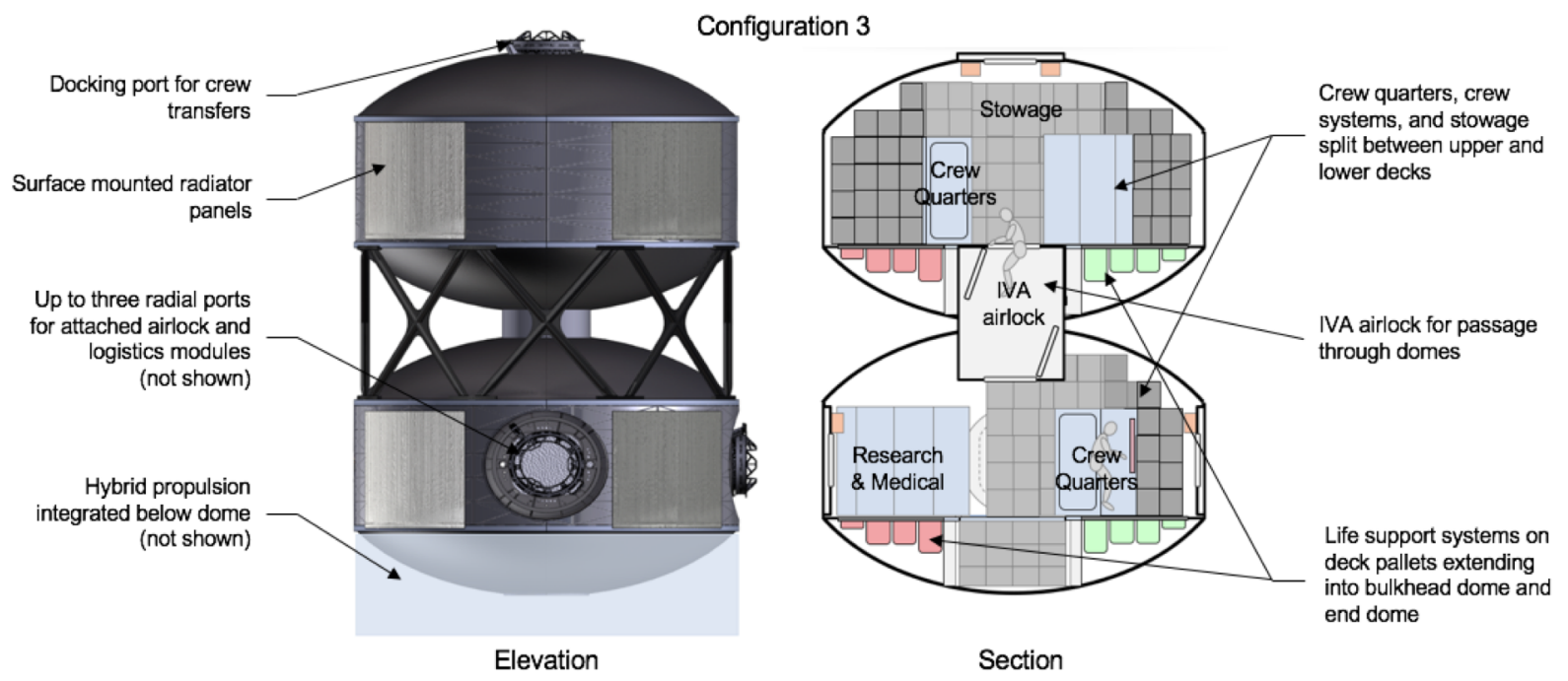

Figure 3. Dual Pressure Vessel Habitat. Configuration 3 separates the two volumes in configuration 2 into two separate pressure vessels of equal size for manufacturing and assembly simplifications. 
Configuration 4 shown in Fig. 4 is a new concept utilizing the pressure vessel volumes planned for the Exploration Upper Stage (EUS), which yielded a convenient large volume habitat with a closed loop system paired with a smaller volume using a 30-day open loop system. The concept is similar to ideas where any attached pressure vessel for logistics could be used as a temporary safe haven if attached to an airlock that permits IVA transfers between volumes. The findings yielded the same basic difference in structures and avionics mass as the full duration habitat, with a much lower mass for the open loop life support system of about $629 \mathrm{~kg}$. The total additional mass for the 30-day safe haven is about $3,071 \mathrm{~kg}$. There is additional risk for this approach over the full duration safe haven configurations, because the crew would have only 30 -days to make repairs to the primary volume. Regardless, it is still an improvement that could mitigate some risks. In addition, if a separable logistics module were utilized, disposal could occur in Mars orbit prior to return but after all of the Mars orbital docking operations have passed.

Several additional differences should be noted in the configuration 4 design. The structures using the basic EUS design will yield simplification in overall manufacturing, but the design is optimized for habitat loads. This yielded a lower loading case which permitted a reduced pressure vessel mass of about $2900 \mathrm{~kg}$ lower than the original EUS designed for propellant loads. In addition, the volume available between the two pressure vessels makes it possible to build in an airlock that can be utilized for both IVA transfers and EVA access too. This finding yielded an additional benefit by eliminating the attached airlock required for configurations 1 through 3 .

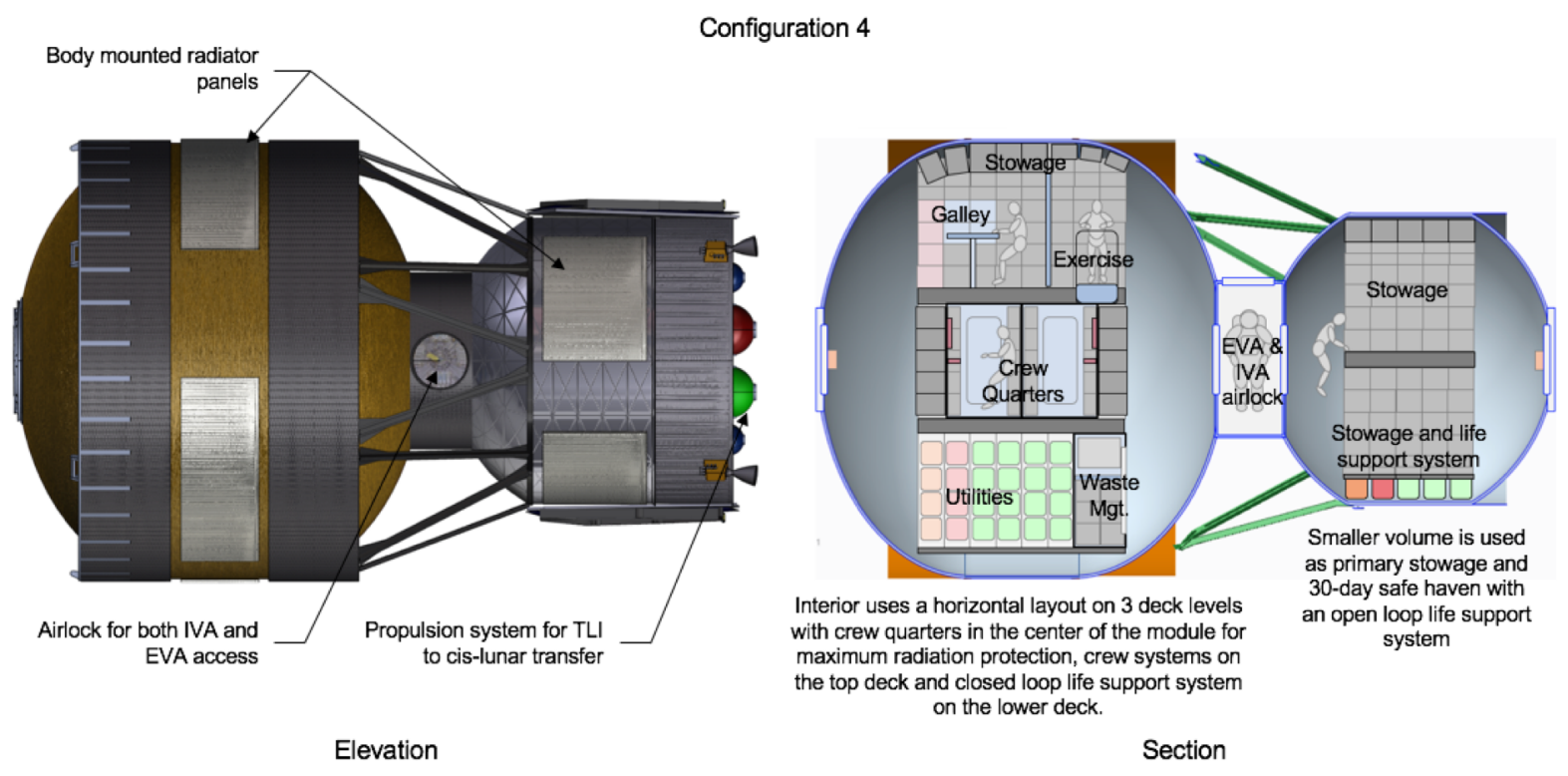

Figure 4. EUS Derived Habitat. Configuration 4 uses the EUS manufacturing capabilities to create a safe haven habitat with the large volume providing a closed loop life support system and the attached smaller volume providing a 30-day safe haven using an open loop life support system.

Configuration 5 shown in Fig. 5 matches the total volume of configuration 4 using two equal pressure vessels and duplicate closed loop life support systems for full duration in either volume. When these two configurations are compared, the results are only about $1500 \mathrm{~kg}$ more for configuration 5, indicating that further optimization of the EUS structural design in configuration 4 may be possible because theoretically the difference should only be the additional $3000 \mathrm{~kg}$ required for the duplicate life support system.

\section{Launch Vehicle Packaging}

Packaging in the SLS payload shroud is another consideration for these configurations as shown in Fig. 6. Configurations 1 through 3 are shown pre-integrated to a hybrid propulsion stage and configurations 4 and 5 use a small built in propulsion system to complete the habitat's transfer to cis-lunar space where it is then assembled to a chemical stage for Mars transfer missions. ${ }^{5}$ The habitat grows in length slightly for each configuration, which does 
impact the overall architecture approach. The complete Mars transit vehicle for each configuration is shown in Appendix A, Figs.7-10.

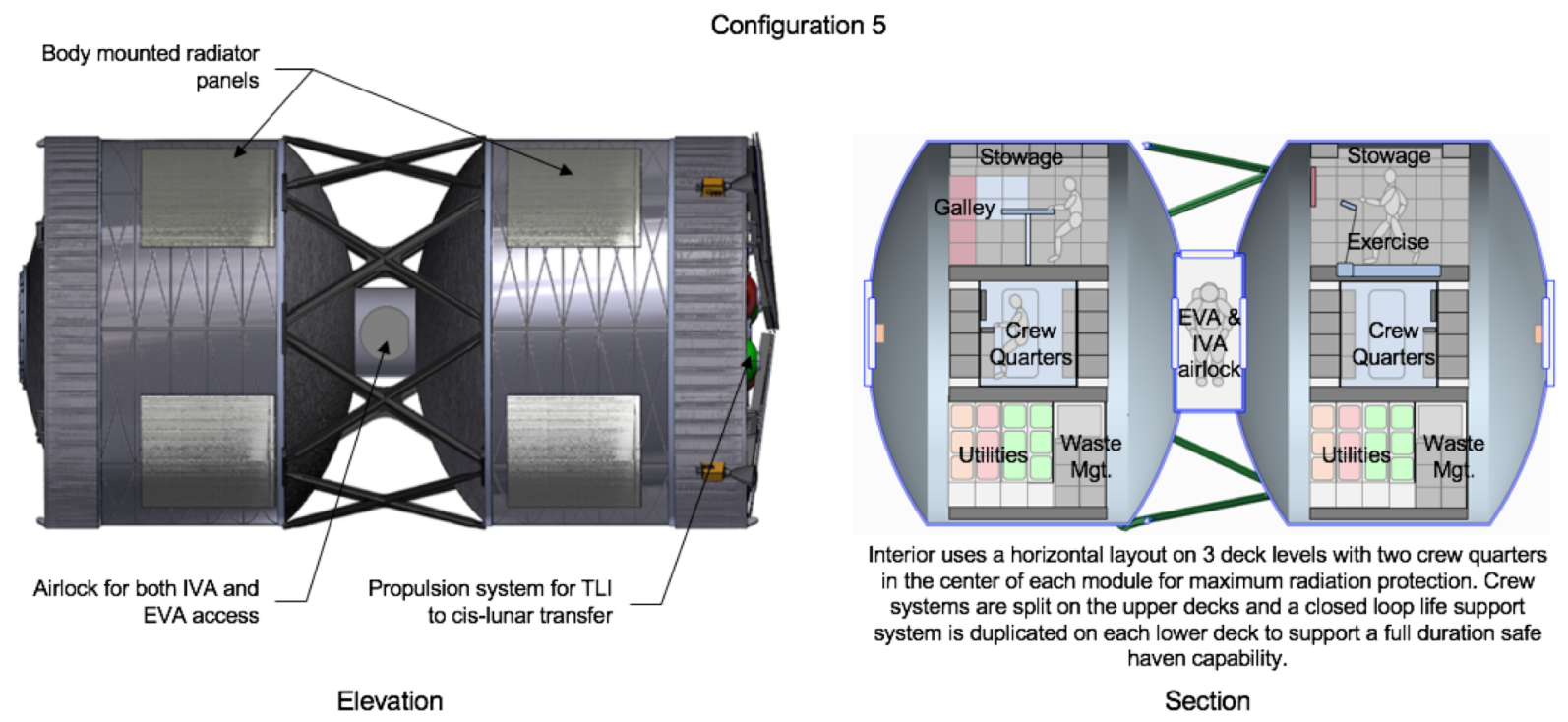

Figure 5. Dual Pressure Vessel Habitat. Configuration 5 separates the total volume provided by the EUS derived habitat in configuration 4 with a 30-day safe haven into two pressure vessels of equal size with a full duration safe haven capability.
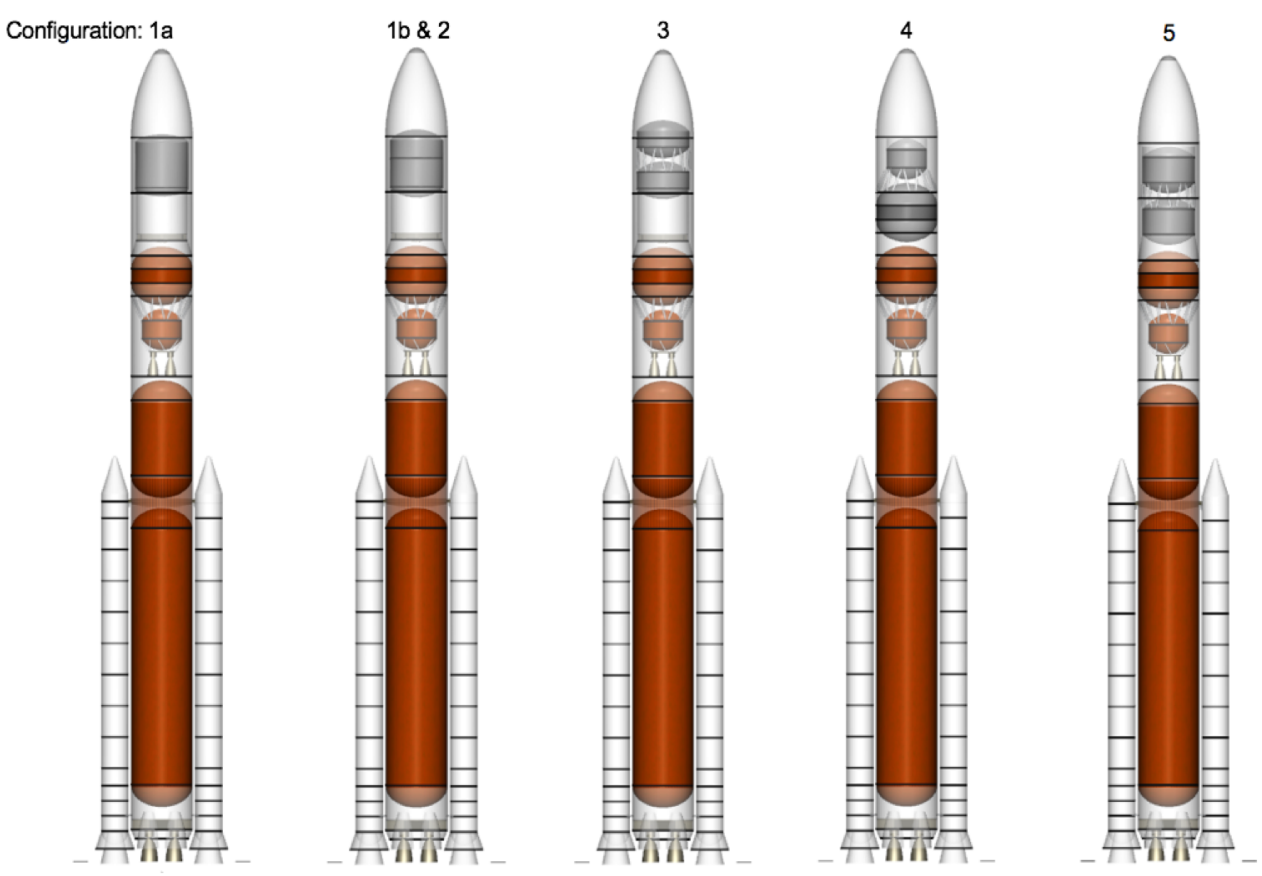

SLS using a standard long fairing, except 4 , which uses a short fairing in a long configuration

Figure 6. Launch Vehicle Packaging. Configurations 1 through 3 are packaged with a large hybrid propulsion system designed for Mars transfer, whereas configurations 4 and 5 are packaged with a small chemical propulsion system designed to complete the transfer from TLI to a cis-lunar orbit where final assembly to a Mars transfer stage is accomplished. 
Configuration 1 shown in Fig. 1 represents the baseline approach from the EMC's Mars transit habitat. The modifications made from configuration 1a to configurations $1 \mathrm{~b}$ and 2 for utilization of standard end domes and increasing volume to accommodate current packaging efficiencies, increased the overall habitat module length by $1.6 \mathrm{~m}$. Configuration 3 grew an additional $1.4 \mathrm{~m}$ with the dual pressure vessel approach. All of these configurations appear to package in the standard shroud currently planned for SLS payload flights. It should be noted however, that growth in the habitat length will place limitations on growth of the hybrid propulsion stage.

Configuration 4 using the EUS manufacturing capabilities is a unique option. Its overall length grew about $6.3 \mathrm{~m}$ beyond the original 1a configuration, which precluded packaging with the hybrid propulsion stage, even though part of the habitat could be extended into the nose cone volume. In addition, a section of the habitat is the same diameter as the core stage and will be exposed to aero loads during launch. This section will likely require aero shell panels to protect the surface of the habitat module where surface mounted radiator panels are likely. Another alternative would be to utilize a $10 \mathrm{~m}$ diameter payload fairing to completely encapsulate this habitat configuration.

Configuration 5 is about $5.7 \mathrm{~m}$ longer than configuration 1a, which also precluded use of the hybrid propulsion system. So, like configuration 4 , a separate propulsion element was planned.

\section{Findings and Recommendations}

The primary mass drivers for the safe haven were found to be in structures, avionics, and the life support system, which totaled about $3000 \mathrm{~kg}$ for a 30 -day safe haven and about $5000 \mathrm{~kg}$ to $6000 \mathrm{~kg}$ for a full duration safe haven.

\section{A. Structures:}

The internal bulk shown in Configuration 2 was found to be nearly three times more massive than a standard end dome due to the requirement for supporting pressure loads from either side which places the dome in a possible tension or compression load. As a result, it was found that there is little mass difference between a pressure vessel with an internal bulkhead and two separate pressure vessels. The bulkhead design provided a more compact solution but requires an additional airlock for EVA access outside the habitat. The dual pressure vessel solution offers simpler manufacturing, possible use of the IVA airlock for EVA access too, but is much longer and less compact. In total, the additional structures mass was found to be around $1700 \mathrm{~kg}$ for both bulkhead and dual pressure vessel options.

\section{B. Avionics:}

Most of the internal avionics, consisting primarily of communications and data handling equipment, was duplicated to provide a complete system inside each pressure vessel. It was noted that the highest risk for pressure loss would be from collision during docking operations when communications, data handling, and vehicle controls would be critical. In total, the additional avionics mass was found to be around $742 \mathrm{~kg}$.

\section{Life Support Systems:}

Two life support systems were investigated to provide a 30-day safe haven using an open loop life support system and a full duration safe haven using a duplicate closed loop life support system. Several options are possible for each approach.

The 30-day open loop system has an overall mass of about $629 \mathrm{~kg}$ for hardware and consumables to support a crew of four. Options available include increasing the duration up to 60 days, although this would be approaching the breakeven point for going with a closed loop life support system.

The full duration closed loop life support systems has an overall mass of about 3,527 $\mathrm{kg}$ based on current ISS technologies. The benefit for using this system is that it has a known reliability for long term use, so planning for maintenance, repair, sparing of components, supplying of filters and consumables is understood. The primary issue is that it is over sized with capabilities to support a crew of 11. An alternative is to down size the system to support a crew of 4 with more advanced technology. This approach is believed to save about $1000 \mathrm{~kg}$ or more in hardware mass and consumables yielding the variation stated above for full duration safe havens in the $5000 \mathrm{~kg}$ to $6000 \mathrm{~kg}$ range.

\section{Additional Findings:}

Every time a new study is done with internal layouts there are additional findings and inputs that warrant consideration in both the requirements and in future design iterations. Here are some of the findings from this study that are noteworthy.

1) External viewing: Based on the ISS experience there is a preference that windows be provided for external viewing from the habitat as well as cameras for external views of the habitat and approaching vehicles. The EMC Mars transit habitats represented by configurations 1 through 3 include view ports in each of the 
docking port hatches, or 5 windows when counting the forward hatch, three radial hatches, and a standard Window Observational Unit in the $4^{\text {th }}$ radial port position. The remaining views were planned to be covered by high definition cameras and internal screens. Configurations 4 and 5 did not include radial ports, so one Window Observational Unit was provided in a radial position and a forward and aft view port in each docking hatch were included. It is not clear if these provisions are sufficient for the mission duration planned, and so further consideration is recommended.

2) Propulsion systems: Habitat configurations 1 through 3 were pre-integrated with a large hybrid propulsion system for the initial transfer to cis-lunar space. The hybrid system includes a large solar electric propulsion (SEP) system, ${ }^{6}$ so some avionics and most of the power systems are on the propulsion element. Once in cislunar space the habitat is loaded with logistics and the hybrid propulsion system is re-fueled in preparation for the crew's journey to Mars. The greater length of configurations 4 and 5 precluded the pre-integration of the hybrid system so an alternative chemical system was utilized. It includes a small integrated propulsion system for the initial transfer from Trans-Lunar Injection (TLI) to cis-lunar space where it is then loaded with logistics and berthed to chemical propulsion stages for the transfer to Mars. In Mars orbit the habitat berths with another set of propulsion stages that have been pre-deployed for the return trip. All avionics and power systems are integrated as part of the habitat element.

3) Power systems: The power requirements for all configurations were about the same since they all had similar requirements to support 4 crew for 1100 days. Habitat configurations 1 through 3 draw power from the solar arrays provided by the SEP system on the hybrid propulsion stage, whereas configurations 4 and 5 utilize a set of deployable solar arrays sized for the habitat power requirements in Mars orbit.

4) Thermal systems: The thermal requirements for all configurations were also about the same since they had similar thermal loads. Each utilized both passive and active systems with body mounted radiators. The possible exception of note is configuration 4 where the diameter of the larger module is the same as the core stage. Several options were discussed including the use of body mounted radiators with an aero shell for protection during launch, enclosure in a $10 \mathrm{~m}$ diameter payload fairing, or deployable radiators located inside the fairing on the smaller safe haven module.

5) Waste management: A noted benefit for the full duration safe haven is that a second waste management compartment is also included.

6) Stowage systems: Long-term stowage of food is a concern in the radiation environment of space and may require greater utilization of refrigeration and freezer units than currently planned. In addition, the impact on food packaging and life support consumables if exposed to vacuum is not fully understood. Duplicate stowage was not considered in the mass estimates for these safe haven configurations and so additional research is needed to confirm that packaging and food stores can survive the potential for explosive decompression and cold when going to vacuum. All configurations were found to have limited packaging volume except configuration 4. Configurations 1 through 3 and 5 required a higher packaging density than currently used on ISS. Acceptable packaging densities need to be confirmed.

7) Research systems: All configurations used a reduced mass and only one research station in the layout for research systems. Concern over the reduction of research equipment and associated volume along with the packaging density concerns for stowage are among the reasons for exploring the larger volumes shown in configurations 4 and 5.

8) Concept of operations: A detailed concept of operations for safe havens is needed to examine a variety of scenarios where their use might be required to prevent loss of mission and/or loss of life. Going through the concept of operations analysis should help generate better requirements that can be applied to more detailed design solutions.

9) Interior layouts: Configuration 1 uses a vertical layout on two deck levels with open circulation between levels similar to the way Skylab was designed. Large crew quarters are provided in a horizontal orientation for the bunk area with the intent of applying this design towards surface habitats and artificial-g configurations. Configurations 2 and 3 are the same, but the open space is restricted by the addition of a bulkhead/dome and an IVA airlock. Configurations 4 and 5 use a horizontal layout on three deck levels with vertical circulation through each end dome. The layout is intended for in-space use only so the crew quarters are in a vertical orientation with sleeping bags on the walls as done in the ISS crew quarters. In general, the vertical layout appears to provide more open public space for the small volume provided, whereas the horizontal layouts appear to provide more private spaces and improved packaging efficiency. The packaging efficiency improvements include opportunities for additional workstations, easier access to stowage along the outside walls, and a separate utility room as opposed to packaging utilities under the floor in the end domes. In addition, the vertical layouts locate the crew quarters around the perimeter whereas the horizontal 
layouts locate the crew quarters in the center of the module providing the possibility for maximizing radiation protection using stowage and habitation systems. ${ }^{7}$

\section{Conclusion}

Conclusions include a variety of findings from the study indicating a need for further research and the development of concepts of operations for various risk scenarios where safe havens could prevent loss of mission and/or loss of life. One issue is that the full duration safe haven configurations require transfer of consumables from the damaged volume to the duplicate volume, which presented concerns over the survival of some consumables in the vacuum of space. The mass delta for the full duration safe haven can be found by comparing configuration $1 \mathrm{~b}$ to 2 and 3 , with a total mass delta on the order of $5,000 \mathrm{~kg}$ to $6,000 \mathrm{~kg}$ due primarily to the structural mass required to create duplicate volumes, duplicate avionics, and duplicate life support systems. The 30-day safe haven has operational concerns as to whether repairs to the primary habitat can be accomplished in the time allocated. The mass delta can be found by comparing configuration 4 to the other configurations which provided a 3,000 $\mathrm{kg}$ reduction in life support mass when using a 30-day open loop system in lieu of a second closed loop life support system. In addition, it should be noted that the 30-day safe haven can also be accomplished with an attached logistics module to an airlock. Such configurations should be explored including options for disposal of logistics waste at Mars prior to return.

\section{Appendix A}

\section{Vehicle Configurations}

The following section provides figures that illustrates the complete vehicle configuration for each of the Mars transit vehicles considered for the safe haven study.

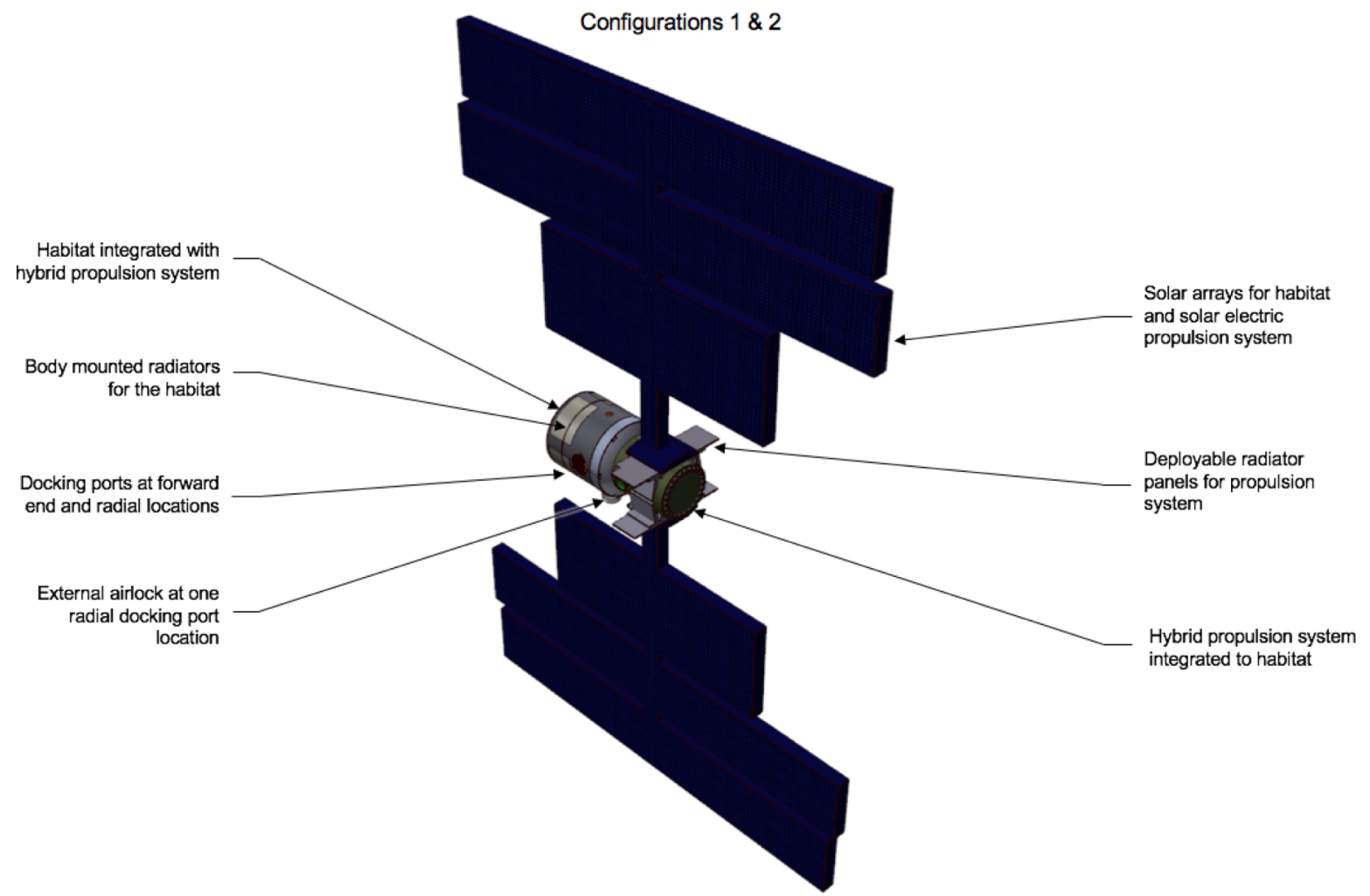

Figure 7. Vehicle Configurations 1 and 2. Configuration 1 uses a monolithic habitat and configuration 2 uses the same habitat with an interior bulkhead to provide safe haven capabilities, both integrated to a hybrid propulsion system for Mars transfer missions. 


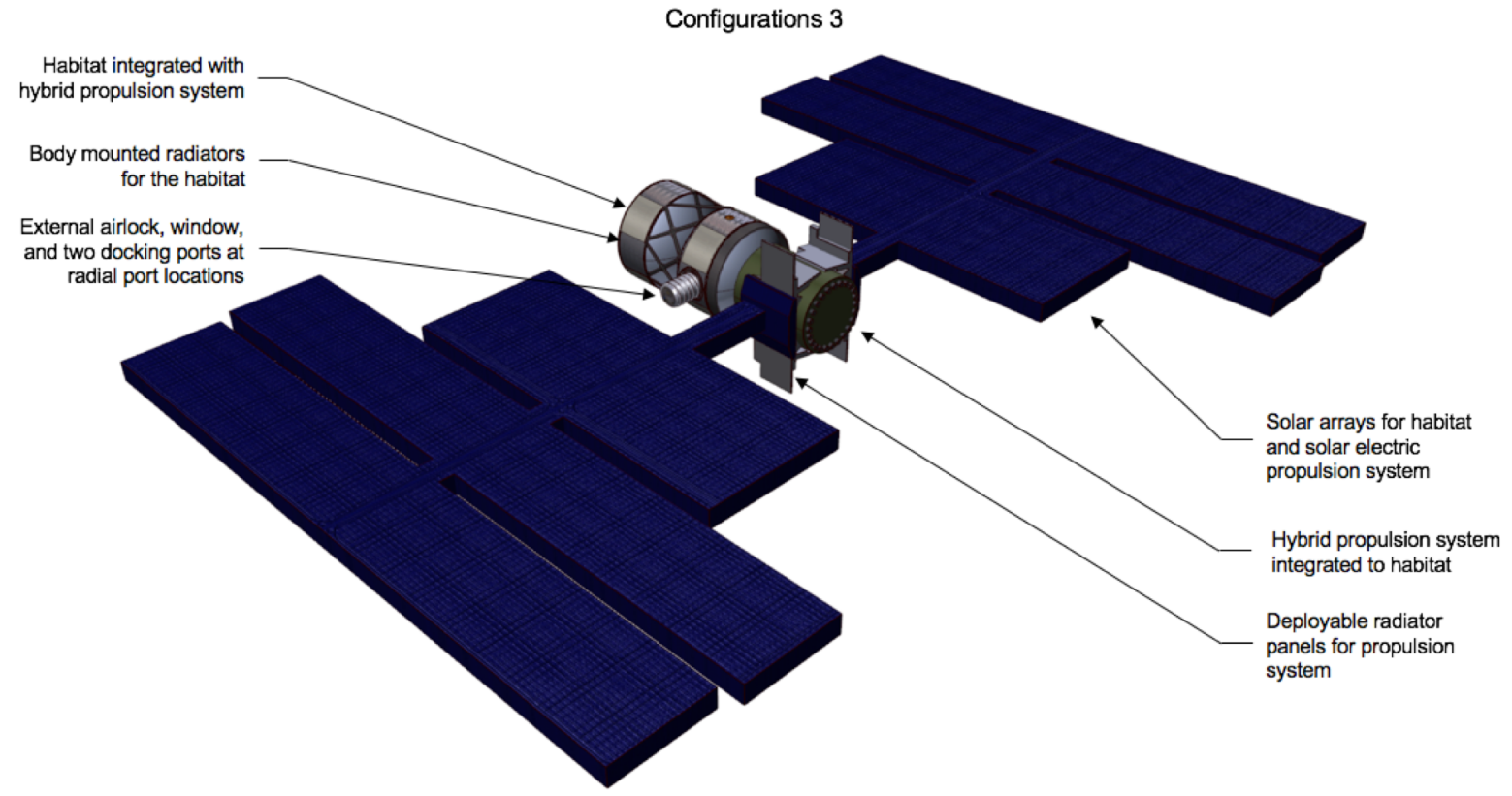

Figure 8. Vehicle Configuration 3. Configuration 3 uses dual pressure vessels to provide a full duration safe haven integrated to a hybrid propulsion system for Mars transfer missions.

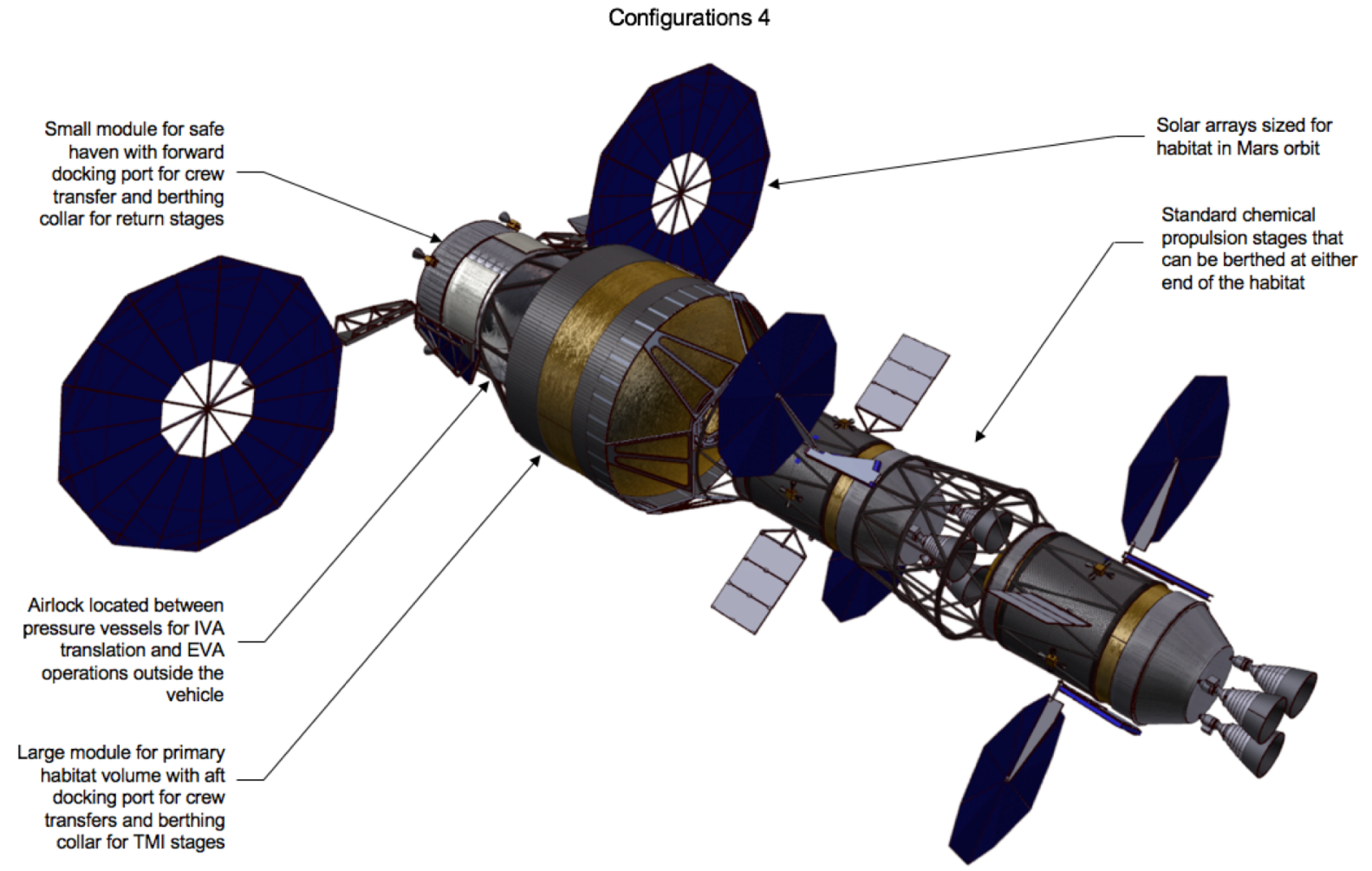

Figure 9. Vehicle Configuration 4. Configuration 4 uses a large pressure vessel as the primary volume and a second smaller pressure vessel as a 30-day safe haven in a configuration using EUS manufacturing capabilities attached to chemical propulsion stages for Mars transfer missions. 


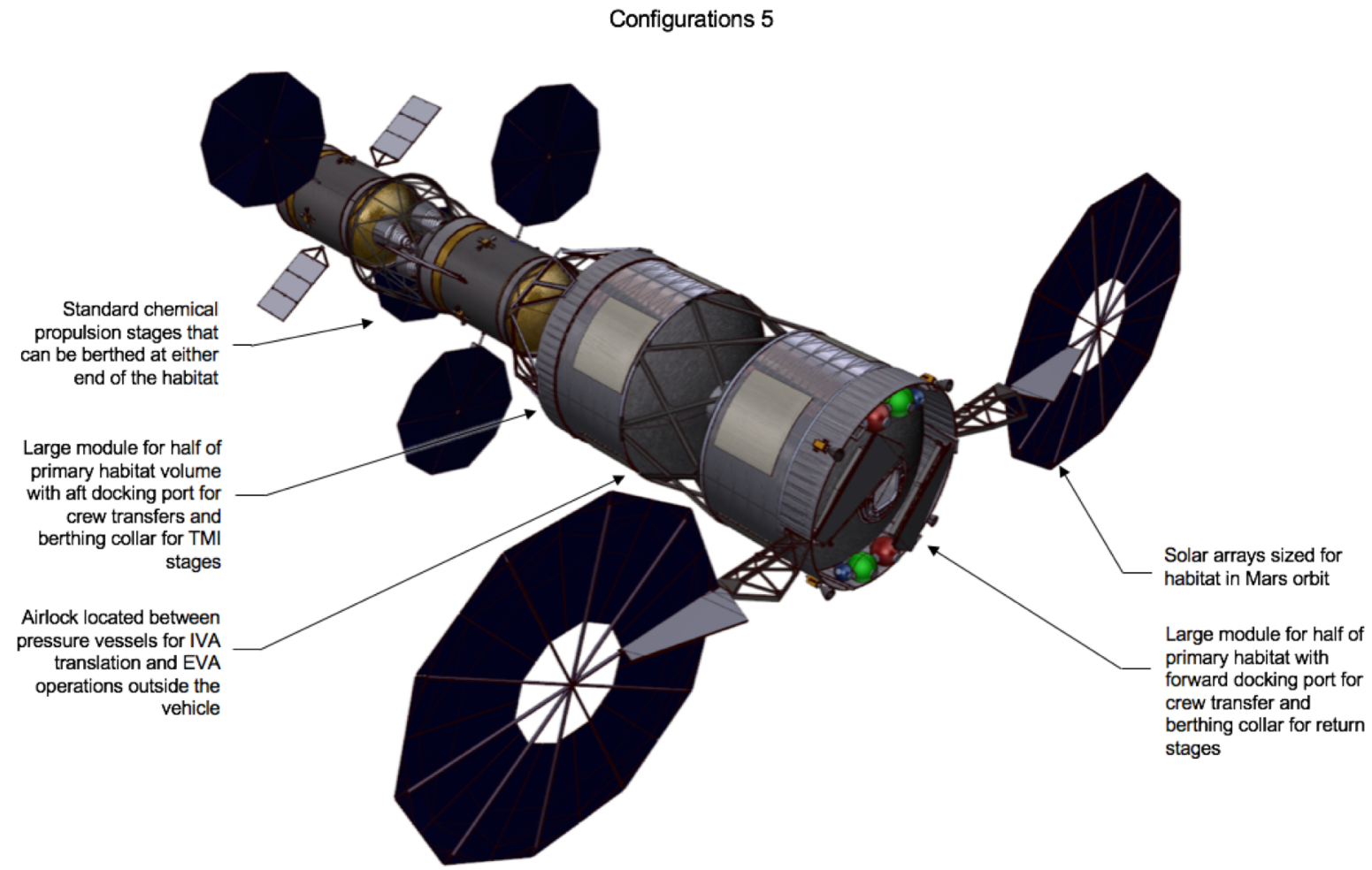

Figure 10. Vehicle Configuration 5. Configuration 5 uses dual pressure vessel to provide a full duration safe haven in each volume, attached to chemical propulsion stages for Mars transfer missions.

\section{Acknowledgments}

The study activities reported in this paper were supported by the NASA Headquarters' Advanced Exploration Systems Program, Evolvable Mars Campaign, Exploration Habitat task managed by Matt Simon at the Langley Research Center, and supported by Tara Polsgrove at the Marshall Space Flight Center. Primary study participants from which this data was produced included David Smitherman as study lead with Mike Baysinger, Jay Garcia, Justin Rowe, David Tabb, Leo Fabisinski, Pete Capizzo, Andrew Schnell, Steven Sutherlin, Tom Percy, Dan Thomas, Jack Chapman, and Alan Philips, for the Advanced Concepts Office, Engineering Directorate, at the NASA Marshall Space Flight Center.

\section{References}

${ }^{1}$ Craig, D. A., P. Troutman, N. B. Herrmann, "Pioneering Space Through an Evolvable Mars Campaign," AIAA SPACE 2015 Conference and Exposition, AIAA 2015-4409, Pasadena, CA, 2015.

${ }^{2}$ Goodliff, K., P. Troutman, D. Craig, J. Caram, N. B. Herrmann, "Evolvable Mars Campaign 2016 - A Campaign Perspective," AIAA Space 2016 Conference and Exposition, AIAA 2016-5456, Long Beach, CA, 2015.

${ }^{3}$ Simon, M. A., L. Toups, A. S. Howe, S. Wald, "Evolvable Mars Campaign Long Duration Habitation Strategies: Architectural Approaches to Enable Human Exploration Missions," AIAA SPACE 2015 Conference and Exposition, AIAA 2015-4514, Pasadena, CA, 2015.

${ }^{4}$ Cerro, J., K. Latorella, M. Simon, et.al., "Development of Logistics for Building Radiation Storm Shelters and their Operational Evaluation," AIAA SPACE 2015 Conference and Exposition, AIAA 2015-4402, Pasadena, CA, 2015.

${ }^{5}$ Percy, T. K., M. McGuire, T. Polsgrove, "In-Space Transportation for NASA's Evolvable Mars Campaign,” AIAA SPACE 2015 Conference and Exposition, AIAA 2015-4519, Pasadena, CA, 2015.

${ }^{6}$ Mercer, C. R., M. L. McGuire, S. R. Oleson, M. J. Barrett, "Solar Electric Propulsion Concepts for Human Space Exploration," AIAA SPACE 2015 Conference and Exposition, AIAA 2015-4521, Pasadena, CA, 2015.

${ }^{7}$ Smitherman, D., "Habitation Concepts for Human Missions Beyond Low-Earth-Orbit," AIAA Space 2016 Conference and Exposition, AIAA 2016-5216, Long Beach, CA, 2016. 